\title{
Enkele metodologiese implikasies van hedendaagse vakfilosofiese kwessies rondom die Historiese Opvoedkunde
}

\author{
Willem Postma \\ Departement Fundamentele en Historiese Opvoedkunde \\ Potchefstroomse Universiteit vir $\mathrm{CHO}$ \\ POTCHEFSTROOM
}

\begin{abstract}
Contemporary topical historico-educational issues force the educational historian to reflect repeatedly on both the study method and the subject philosophy underlying the choice and application of the latter method. It is angued that a thorough knowledge of and insight into certain historico-educational subject philosophical bases which determine the choice and application of the method of history of education can lead to more valid and reliable conclusions and findings in the field of the history of education.
\end{abstract}

\section{INLEIDING}

Hoewel die Historiese Opvoedkunde al sedert 1775, mar veral vanaf die begin van die twintigste eeu (Coetzee, 1977:11) 'n erkende deeldissipline van die opvoedkunde is en sy eie ondersoekmetode en wetensterrein het (vergelyk Barnard, 1978), het dit vanweë snelle ontwikkelinge op onderwysgebied gedurende die afgelope aantal dekades nodig geword om opnuut oor die vakfilosofie en by gevolg die navorsingsmetode van die Historiese Opvoedkunde te besin.

In hierdie artikel sal daar dus veral oor enkele vakfilosofiese kwessies wat die historiesopvoedkundige metode ten grondslag lê, besin word - ook omdat daar (in die onlangse verlede en) tans groot histories-opvoedkundige navorsingsprojekte oor aktuele onderwysaangeleenthede geloods (is) word. So word daar byvoorbeeld in Suid-Afrika navorsing oor die geskiedenis van onderwys vir swartes in Suid-Afrika (Van der Walt, J.L., 1990) onderneem, en in die Verenigde State van Amerika het Lowe en Kantor (1989) ondersoeke na onderwyshervorming in die VSA sedert 1960 gedoen, terwyl Cunningham (1989) die afgelope dekade navorsing oor Engelse historiografie en opvoedkundige veranderinge gedoen het.

Die navorsing wat Grundlingh (1990) byvoorbeeld onderneem het oor die (gebrekkige) objektiwiteit wat sommige Suid-Afrikaanse historici se navorsing kenmerk (vergelyk 
Metodologiese implikasies van vakfilosofiese kwessies rondom die Historiese Opvoedkunde

2.4), plaas die hele vraagstuk van wat die vakwetenskaplike se vakfilosofie is en watter invloed sodanige filosofie op die keuse van sy metode het, in die brandpunt. Smith (1988:2) se bewering dat dit in die Suid-Afrikaanse konteks moeilik is om 'n tradisie van geskiedskrywing te vind "that was more preoccupied with the contemporary situation than Afrikaner nationalist historiography", bevestig verder die noodsaaklikheid dat daar besin moet word oor die vakfilosofie (waaronder ook die vraagstukke van objektiwiteit en subjektiwiteit) wat die keuse en aanwending van die historiese metode bepaal.

Die probleem wat Smith (1988) en Grundlingh (1990) met die Afrikaanse geskiedskrywing ondervind, is na alle waarskynlikheid ook 'n probleem van sommige Afrikaanse histories-opvoedkundige skrywers. Alhoewel daar, sover vasgestel kon word, nog nie op dieselfde wyse as wat Smith na Afrikaanse historici se werke gekyk het, ondersoek na histories-opvoedkundige werke ingestel is nie, bestaan die vermoede dat skrywers soos Coetzee (1977), Du Toit (1970), Postma (1983) en Barnard (1979) ook sterk onder die invloed was van sekere fasette van hulle volk se geskiedenis as toelaatbare veranderlikes in hulle strewe na objektiwiteit.

Bisschoff (1981) en Pienaar (1984), eksponente van die metapedagogiese en temporaliteitspedagogiese denkrigtings, se werke dui wel daarop dat hulle dit erns maak met die vraagstuk van objektiewe geskiedskrywing in opvoedkunde.

Bisschoff (1981:3-4) beweer dat 'n metode bloot 'n denkweg of 'n ontsluitingsweg is om tot die waarheid oor 'n saak te kom. Daar mag egter nie, volgens hom, slegs van een metode gebruik gemaak word in die wetenskaplike ondersoek nie, want die aanwending van verskillende metodes verhoog die moontlikhede om tot die waarheid te kom. Hy voeg hierby dat die tematologiese of probleemhistoriese ondersoekmetode die een ondersoekmetode is wat hom by uitnemendheid leen tot 'n pedagogiese ondersoek van die verlede. Daarom word daar in paragraaf 2.5.2 dieper op laasgenoemde metode ingegaan.

Pienaar (1974:18 e.v.) met sy temporaliteitspedagogiek en Janusbeeld ('n visie van die verlede en die toekoms) vestig verder veral die aandag op die ontiese trias, naamlik verlede, hede en toekoms. Hy onderskei verder tussen drie vorme van tydsbegrip, naamlik objektiewe tyd, sikliese tyd en chronologiese tyd. Pienaar (1974:35) gee toe dat die temporaliteitspedagogieker van die historiese metode gebruik moet maak, maar sonder ' $\mathrm{n}$ fenomenologiese interpretasie is daar vir hom nog geen sprake van pedagogiek nie. Ook die eksemplariese en metabletiese metodes (Pienaar, 1974) behoort aangewend te word in die histories-opvoedkundige ondersoek. Pienaar toon dus, met die hulp van 'n verskeidenheid metodes, die weg aan wat gevolg kan word om tot optimale geldige en betroubare (i.c. 'objektiewe') bevindinge te kom in, soos hy dit 
noem, temporaliteitspedagogiek.

Of Bisschoff en Pienaar daarin slaag om tot objektiewe bevindinge te kom, is ' $n$ studieveld op sy eie en 'n afsonderlike artikel wat op hierdie faset van die probleem van objektiewe opvoedkundige geskiedskrywing fokus, is nodig. In hierdie artikel val die klem veral op die probleem-historiese metode as werkweg van die reformatorieshistories-opvoedkundige.

Gesien teen bogenoemde agtergrond, en om die gesprek rondom sekere vakfilosofiese vraagstukke aan die gang te sit, het dit spesifiek vir die histories-opvoedkundiges weer eens nodig geword om juis oor objektiwiteit en subjektiwiteit as vakfilosofiese vraagstukke te besin.

Dit is verder nodig om oor 'n vakfilosofiese saak soos die invloed wat 'n lewens- en wêreldbeskouing op die aanwending van metodes soos hermeneutiek en heuristiek in die Historiese Opvoedkunde uitoefen, te besin (vergelyk Smith, 1988 en Grundlingh, 1990). Metodes is ook nie, soos veelal aanvaar word, losstaande van lewens- en wêreldbeskouings nie. Sover vasgestel, is daar lanklaas hier te lande (waarskynlik in J. Chris Coetzee en I.S.J. Venter se tyd in die sewentigerjare) spesifiek oor bogenoemde vraagstuk in die beoefening van Historiese Opvoedkunde as wetenskap besin.

Die deursnee-navorser wat 'n histories-opvoedkundige projek onderneem, maak vanuit 'n bepaalde hoek of posisie (hy vorm deel van 'n volk, het 'n eie kultuur, is gebind aan 'n religie en lewe in 'n spesifieke tyd) keuses ten opsigte van die wetenskaplike metodes wat hy aanwend. Sulke keuses word gerig deur sy lewens- en wêreldbeskouing. Sodra daar oor die lewens- en wêreldbeskouing (i.c. lewensopvatting/oortuigingsraamwerk) van die wetenskaplike besin word, kom die filosofie wat die dissipline (i.c. metode) ten grondslag lê en rig (dit wil sê die vakfilosofie) ter sprake (De Klerk, 1981; Grundlingh, 1990; Borg \& Gall, 1989; Barnard, 1978; Coetzee 1977; Stoker, 1961 en 1970; Van den Berg, 1990; Smith, 1988; Van der Schijff, 1991; Venter, 1976 en Wiersma, 1986).

Die vraag wat dus in hierdie artikel aan die orde kom, is watter rol die historiesopvoedkundige se vakfilosofie speel in die keuse en aanwending van sy wetenskaplike metodes.

Vir die beantwoording van die vraag is dit nodig om oor enkele histories-opvoedkundige vakfilosofiese grondslae (vergelyk 2.1) duidelikheid te kry. Algaande moet daar besin word oor hoe hierdie grondslae die keuse en implementering van wetenskaplike metodes beïnvloed, waarna daar tot 'n slotbeskouing gekom kan word. 


\section{ENKELE VAKFILOSOFIESE UITGANGSPUNTE EN HULLE METODOLOGIESE IMPLIKASIES}

\section{$2.1 \quad$ Vooraf}

In die omskrywing van die term historiese opvoedkunde self kan alreeds sekere (filosofiese) benaderingswyses en verklarings bespeur word; daarom is dit nodig om kortliks stil te staan by 'n begripsverheldering van die term historiese opvoedkunde.

In hierdie paragraaf sal verder ook in hooftrekke besin word oor enkele filosofiese vraagstukke met betrekking tot die beoefening van Historiese Opvoedkunde as wetenskap. Die filosofiese vraagstukke wat aan die orde kom, is:

* die plek en rol van 'n lewensopvatting in die werksaamhede van die historiesopvoedkundige;

- objektiwiteit en subjektiwiteit as vraagstuk in die beoefening van die Historiese Opvoedkunde as wetenskap.

Daar sal verder gepoog word om te toon hoe die histories-opvoedkundige te werk kan gaan om sy gekose metode te versoen met sy lewens- en wêreldbeskouing (en vakfilosofie).

\subsection{Begripsverheldering}

Die wetensgebied bekend as Historiese Opvoedkunde dui daarop dat hierdie wetenskap 'n (deel-)dissipline van die opvoedkunde is, 'n dissipline wat hom besig hou met die studie van die verskynsel opvoeding soos dit sigself deur die eeue gemanifesteer het (Barnard, 1978:10). Cronje (1967:111-113) is van mening dat die Historiese Pedagogiek "' $n$ beligting, ' $n$ verheldering, ' $n$ interpretasie en 'n evaluering van die pedagogiese bemoeiinge van die mens in die verlede (is), omdat daaruit meer vrugbare toekomstige pedagogiese handelinge kan voortspruit". Coetzee (1977:1) se omskrywing van die Historiese Opvoedkunde stem hoofsaaklik met bogenoemde uiteensettings ooreen, maar hy voeg by dat hierdie (deel)dissipline sy eie metodes van ondersoek, sy eie taak, plek en betekenis in die ry van die opvoedkundige onderdele of dissiplines het.

Uit bogenoemde volg dit dat die Historiese Opvoedkunde:

- 'n (deel)dissipline van die opvoedkunde is;

* 'n eie ondersoekterrein, naamlik die opvoedende onderwysverlede, het; 
* 'n eie metode het;

- gemoeid is met die beoordeling van versamelde historiese (onderwys-)gegewens, en

- oor sy eie beoefenaars beskik.

Bogenoemde presisering van die begrip historiese opvoedkunde dui daarop dat sekere mense ('beoefenaars') dié wetenskap beoefen deur die gebruikmaking van bepaalde wetenskaplike metodes. Die mens is 'n religieuse wese (Van der Walt \& Dekker, 1983:78 e.v.) wat in die keuse en aanwending van sy metodes deur beginsel-, norme- en waardesisteme gerig word (Stoker, 1961). In sy beoordeling van gegewens sal bogenoemde lewensopvatlike gesitueerdheid van die 'beoefenaar' noodwendig 'n rol speel.

2.3 Die plek en rol van die lewensopvatting in die werksaambede (met name die metode-toepassing) van die histories-opvoedkundige

Die wetenskaplike verklaring van histories-opvoedkundige gegewens hou meer in as bloot die deskriptiewe weergawe van gegewens - dit sluit ook die prinsipiële beoordeling, in ooreenstemming met die oortuigingsraamwerk van die beoefenaar - van sodanige inligting in. So dui Coetzee (1977:1) aan dat die histories-opvoedkundige wetenskap 'n (ana- of apostatiesgerigte) norm van waardering, goed- en afkeuring aanlê "want die historiese opvoedkundige moet as opvoedkundige wat al sy gegewens, ook sy historiese gegewens, wil aanwend by die opvoeding, 'n oordeel uitspreek oor die gegewens". De Klerk (1981:147-149) sluit hierby aan as hy aandui dat 'n geskiedskrywer hom nie geheel en al kan losmaak van beoordeling nie, al heers die opvatting dat dit nie die taak van die historikus is om oordele te vel nie. Hierdie beoordeling deur die histories-opvoedkundige vorm deel van sy ondersoekopdrag en -metode. Laasgenoemde ondersoekmetode is nie los te maak van die navorser se lewensopvatting nie, want beweer De Klerk (1981:11), "onder die verskillende buitewetenskaplike faktore wat wetenskaplike ondersoek, ook in geskiedkundige en die geskiedfilosofie, beïnvloed, speel die lewens- en wêreldbeskouing of 'die geheel van antwoorde op fundamentele vrae aangaande God (of wie ook al afvallig in die plek daarvan gestel word), mens en wêreld in hul onderlinge verhoudinge'... 'n belangrike rol".

Omdat, soos hierbo aangedui, die histories-opvoedkundige 'n bepaalde siening van God (afgod), mens en wêreld in hulle onderlinge verhoudinge huldig, wil dit nie sê dat hy bevooroordeeld en subjektivisties mag wees in sy versameling en beoordeling van histories-opvoedkundige feite nie. Hy moet hom steeds hou by die waarheid en 'n getroue beeld van sy veld van ondersoek gee. 
Die lewensopvatlike gerigtheid van die histories-opvoedkundige hou egter tegelyk in dat hy nie neutraal kan staan teenoor sy wetenskaplike arbeid nie. Daar is nietemin 'n verskil tussen krities-ingestelde en moraliserende geskiedkunde. Moralisering is nie deel van historiese beoordeling nie, terwyl kritiese ingesteldheid (waaronder beoordeling) 'n goeie kwaliteit wetenskapsbeoefening waarborg. Pienaar (1974:4) kwalifiseer hierdie krities-ingestelde benadering verder deur daarop te wys dat dit in die historiese opvoedkunde gaan om "die pedagogiese waarheid in sy tydloos-geldende wesenlikheid as paedagogia perennes" te omlyn.

Samevattend: Gegewe die feit dat die histories-opvoedkundige deur een of ander lewensopvatting in sy arbeid gerig en beïnvloed word, behoort hy steeds aan homself rekenskap te gee oor presies wat sy lewens-en wêreldbeskouing behels en of sy wetenskaplike arbeid nie subjektivisties neig onder invloed van sy siening van God, mens en wêreld in onderlinge samehang nie.

2.4 Die vraagstuk van objektiwiteit en subjektiwiteit in die beofening van die Historiese Opvoedkunde

Vir die histories-opvoedkundige impliseer subjektivisme dat hy sy eie belange en instelling as mens ' $n$ oordrewe rol laat speel in die opsporing, verklaring en beoordeling van historiese feite. Objektivisme sou weer 'n verabsolutering van die vermoë van die mens om buitekant homself te staan beteken, sonder inagneming van die gegewene dat die mens nie geheel en al neutraal of objektief kan wees in sy wetenskapsbeoefening nie. Volgens Stoker (1970:73) is elke wetenskaplike metode gebind aan sy twee pole, naamlik die uitgangs- of vertrekpunt sowel as aan die eind- of doelpunt, en albei hierdie punte is prinsipieel bepaal.

Van den Berg (1990) dui in verband met historiese navorsing aan dat interpretasie van geskiedgebeure nie los te maak is van subjektiwiteit nie. Hy beweer dat die verlede nooit in sy geheel betrag kan word nie omdat spore van die verlede verdwyn of verstrooi in sowel kontekstuele as ruimtelike sin. Hy redeneer verder dat die mens se bestaan 'n deurlopende eenheid, kontinu is. Die menslike bestaan is dus 'n 'aaneenlopende sin' sonder leestekens, paragrawe en hoofstukke. As sodanig kan die verlede nooit volledig begryp word nie. Al sou volslae objektiwiteit haalbaar gewees het, lè dit nie binne die menslike vermoë om die verlede in sy volle waarheid (en besonderhede) te rekonstrueer nie, omdat

- slegs fragmente van die verlede in die menslike herinneringe en geskrifte oorbly;

- die menslike begrip die volledigheid van die verlede nie kan omvat nie, en 
* die mens as sondige wese die waarheid in sy volheid nie kan deurgrond nie waarheid setel alleen in God.

Weens sy onvermoë tot objektiwiteit en volledigheid is die historikus daarop aangewys om in 'n sekere sin die verlede te tematiseer en te periodiseer. Op dié wyse selekteer hy 'n onderwerp uit die geheel van die verlede. Van den Berg (1990) betoog voorts dat die historikus aan die verlede 'n vereenvoudigde gedaante verleen in sy weergawe en interpretasie daarvan. Die navorsingsterrein word dus gerelativeer. Hieraan gekoppel is subjektiwiteit, want die historikus kies nie slegs sy tema nie, maar ook 'n vertrekpunt en die stof wat hy wil of kan hanteer. Dit bring mee dat die verlede telkens vanuit 'n nuwe standpunt betrag en herbetrag word. Hierdie subjektiwiteit van die historikus word egter aan 'n bepaalde dissipline onderwerp, naamlik dat die lewensopvatlike en wetenskaplike vertrekpunte en standpunte steeds houdbaar en verantwoordbaar moe wees in terme van die betroubaarheids- en geldigheidsreëls wat vir die wetenskappe geld.

In die wetenskaplike werksaamhede van die historikus kan hy hom nie daarvan losmaak dat die interpretasie en sintese van versamelde gegewens 'n skeppende proses is nie, want deur sy interpretasie laat die historikus die verlede herleef. Hy gee lewe aan dooie feite deur die spore van die verlede te vind en te vertolk.

Van den Berg konkludeer sy argument deur daarop te wys dat die belangwekkendheid van die geskiedenis grootliks opgesluit lê in sy subjektiwiteit - met dié voorbehoud dat hoewel objektiwiteit in absolute sin nie haalbaar is nie, die historikus doelbewus die lokvalle van subjektivisme moet vermy. Die volle waarheid in die geskiedenis is dus vir die in sondegevalle mens nie bereikbaar nie, maar vir die eerlike (hoewel onvolmaakte) historikus is deelwaarhede wel haalbaar.

In hierdie verband moet daar ag geslaan word op die waarskuwing van Grundlingh (1990:7) dat so 'n standpunt van toegewing aan subjektiwiteit daartoe kan lei dat sekere 'noodwendige subjektiewe faktore' wat die historikus pas, "could receive authoritative approval as acceptable 'scientific' history". Volgens Grundlingh (1990) het 'n hele geslag Afrikanerhistorici soos S.F.N Gie, J.A. Wiid, H.B. Thom, D.W. Krüger, A.J.H. van der Walt en M.C.E. van Schoor juis in hierdie opsig gesondig deur "various versions of 'volksgeskiedenis" as toelaatbare elemente in hulle objektiwiteitstrewe toe te laat. Tereg beweer Grundlingh (1990:7) dat s6 'n strewe na objektiwiteit (met toegewings aan subjektiwiteit) ' $n$ ingeboude kontradiksie het. So byvoorbeeld mag die verlede nie gebruik word om hedendaagse politieke, sosiale en ekonomiese stande te regverdig nie (Grundlingh, 1990:10). Die historikus moet, in sy strewe na objektiwiteit en die toelaatbaarheid van sy subjektiefmenswees, steeds poog om "a clear and specific view of the world" te bekom, sonder om deur partikuliere politiek

Koers 57(2) 1992:215-226 
gemanipuleer te word.

Samevattend: Wanneer die histories-opvoedkundige feite versamel, orden, verklaar en beoordeel, behoort hy deurlopend vir homself rekenskap te gee of hy gehoor gee aan bogenoemde norme vir objektiwiteit, naamlik:

* die vermyding van subjektivisme;

* suiwere interpretasie van die histories-opvoedkundige gebeure;

* helder rekonstruering van tersaaklike gebeure;

* selektiewe tematisering en periodisering van die onderhawige studieterrein;

* verantwoordbaarheid van vooronderstellings, en

* die uitskakeling van subjektivisme deur die onoordeelkundige toelaat van subjektief-menswees in sy navorsing.

2.5 Verdere metodologiese maatreēls wat geldige en betroubare resultate kan waarborg

\subsubsection{Oriēntering}

In die voorafgaande paragrawe het histories-opvoedkundige metodes soos die opsporing, rekonstruering, tematisering, periodisering, ordening, wetenskaplike verklaring en beoordeling van historiese feite reeds ter sprake gekom, en ook hoe vakfilosofiese oorwegings die aanwending van sulke metodes bepaal. Vir die doel van hierdie artikel word in hierdie paragraaf nog kortliks aandag aan die probleem-historiese metode gegee omdat die aanwending van hierdie (reformatoriese) metode verder daartoe kan bydra dat die histories-opvoedkundige subjektivisme met sorg kan vermy.

\subsubsection{Die probleem-historiese metode}

Die probleem-historiese metode staan onder die filosowe ook bekend as die Konsekwente Probleem-historiese Metode van die Filosofiese Historiografie. Die wese van die metode kom daarop neer dat dié metode konsekwent die filosofiese probleme in hulle historiese gang blootle (Van der Walt, B.J., 1990.) Aangesien bogenoemde metode veral uitgebou is met die oog op en van besondere waarde is vir navorsing in die geskiedenis van die filosofie, maar telkens in histories-opvoedkundige navorsing aangewend word (vergelyk Van der Walt, 1990; Steyn, 1990; De Villiers, 1988 en Eggink, 1990), word hier met enkele winspunte vir die Historiese Opvoedkunde volstaan waarna kortliks aangedui word hoe hierdie metode werk. Die winspunte is: 
- Dit is die enigste werklik reformatoriese Bybels-gefundeerde metode.

- Hierdie metode vervorm nie doelbewus die geskiedenis van die opvoeding en onderwys volgens 'n vooropgestelde skema nie.

- Dit bied 'n nuttige oorsig van die Westerse opvoeding en onderwys.

- Dié metode toon eenheid en verskeidenheid in die geskiedenis van die opvoeding en onderwys aan.

* Dit gee insig in die hooftrekke van opvoedkundige denkers.

* Die verwantskappe tussen verskille en verbande tussen verskillende opvoedkundige denkers word aangetoon.

- Die metode leen hom daartoe om aan te dui hoe en presies op watter punte een opvoedkundige denker 'n ander beïnvloed.

Om ál bogenoemde winspunte te kan waarborg én om die probleme rondom die vakfilosofiese vraagstukke van lewensopvatting, objektiwiteit en subjektiwiteit soos bespreek in 2 te kan akkommodeer, gaan die hist.Jries-opvoedkundige soos volg met behulp van die probleem-historiese metode te werk:

Eerstens behoort die betrokke histories-opvoedkundige al die stappe wat met die probleem-historiese metode gevolg word, op homself toe te pas. Dit impliseer dat hy aan homself rekenskap sal moet gee van presies wat sy eie lewens- en wêreldbeskouing behels en watter religieuse grondmotief sy handelinge ten grondslag lê en rig. Die Christen-histories-opvoedkundige wat dus van die probleem-historiese metode gebruik maak, aanvaar al die so geïdentifiseerde oortuigings as onafhanklike veranderlikes by die aanwending van die histories-opvoedkundige metodes in sy ondersoek. Hy sal byvoorbeeld rekening hou met die feit dat hy as sondige subjek slegs deelwaarhede kan blootle (vergelyk 2.4) van dit wat hy ondersoek (die objek). Hy sal steeds poog om die onafhanklike veranderlikes konstant te hou en in ag te neem ter wille van geldigheid, betroubaarheid en objektiwiteit, maar nie ter wille van neutraliteit nie.

Tweedens identifiseer die histories-opvoedkundige die eietydse opvoedingsprobleem wat hy ondersoek, waarna hy dié besondere probleem in sy historiese konteks plaas en ondersoek. Daar word dus teruggekeer na die kultuur-historiese konteks van die probleem (of van 'n bepaalde filosoof of 'n historiese maghebber of figuur of historiesopvoedkundige van daardie tyd). Op hierdie wyse wend die histories-opvoedkundige 'n poging aan om die oorsprong en verloop van die probleem deur die oë van die des- 
tydse betrokkenes te bekyk. Wanneer die histories-opvoedkundige bogenoemde stappe deurloop het, kan hy voortgaan om die eietydse probleem in sy verskillende fasette te ontleed en te evalueer.

'n Verdere maatstaf vir geldigheid en betroubaarheid wat in die probleem-historiese metode ingebou is, is die feit dat hierdie metode die religieuse grondmotief en die basiese vooronderstellings wat die gedagtes en handelinge van die eertydse maghebber (of histories-opvoedkundige) ten grondslag gele en gerig het, na vore bring. Sy verhouding tot God of afgod word bepaal en die blootle van sy ana- of apostatiese oortuigingsraamwerk plaas die probleem in 'n bepaalde perspektief, sodat bepaal kan word waar en hoe hierdie probleem sy ontstaan gehad het en hoedat dit hom in die huidige opvoedkunde manifesteer of selfs wreek (Van der Walt, 1982:39-40; Van der Walt, 1988:224 en Steyn, 1990:6).

Ten slotte sal die histories-opvoedkundige as Christen-wetenskaplike, gerig deur sy vooronderstellings as onafhanklike veranderlikes, in gesprek tree met die maghebber (of die onderhawige probleem), die probleem dienooreenkomstig verklaar en beoordeel en op hierdie wyse steeds nader aan objektiwiteit en toelaatbare subjektiwiteit beweeg in sy navorsingsbevindinge.

\section{SLOTBESKOUING}

Gesien teen die agtergrond van die voorafgaande argumente sal die opsporing, rekonstruering, tematisering, periodisering, ordening, wetenskaplike verklaring en beoordeling van histories-opvoedkundige feite moet plaasvind in ooreenstemming met die histories-opvoedkundige se lewensopvatting. Die reformatories-gerigte historiesopvoedkundige se siening van die werklikheid, waaruit hy histories-opvoedkundige feite selekteer en versamel, en ook sy beskouing oor orde as deel van God se wet vir die werklikheid, sal die keuse en aanwending van bogenoemde metodes bepaal. Hy sal byvoorbeeld daarteen waak om in die keuse en aanwending van versameling en ordening as metodes mensgerig (humanisties) of praktykgerig (pragmatisties) te wees, of enige vorm van kosmologiese verabsoluteringsgerigtheid te openbaar, maar sal wel konsekwent anastaties-gerig te werk gaan (vergelyk Schoeman, 1979 en Strauss, 1978).

Op soortgelyke wyse sal die histories-opvoedkundige die metodes van wetenskaplike verklaring en beoordeling kies en aanwend. Hy sal in sy verklaring steeds besef dat hy nie die geskape werklikheid ten volle kan begryp en verklaar nie, en in sy beoordeling van histories-opvoedkundige gebeurtenisse sal sy besef van eie onvolmaaktheid hom weerhou van 'veroordeling' en eensydige (subjektiewe) standpuntinnames. Hy sal voorts van die probleem-historiese metode gebruik maak, nie net omdat hierdie me- 
tode in sy wese 'n Bybels-gefundeerde metode is nie, maar ook om die beperkte en onvolmaakte siening wat die historiese maghebber op die implikasies van sy besluit gehad het, in gedagte te hou by sy beoordeling en verklaring van histories-opvoedkundige gebeurtenisse. Sodoende kan die mees objektiewe wetenskaplike resultate bereik word.

\section{BIBI IOGRAFIE}

BARNARD, S.S. 1978. Inlciding tol die Historiese Opvocdkunde as wetenskap. Potchefstroom : PU vir CHO. 91p.

BARNARD, S.S. 1979. Blanke-onderwys in Transvaal in histories-pedagogiese perspektief. Durban : Butterworth. 206p.

BISSCHOFF, T.C. \& KRUGER, G. 1981. Boustene in die Metapedagogick - van Sparta tot Spencer. Durban : Buttcrworth. 255p.

BORG, W.R. \& GALL, M.D. 1989. Educational Research. New York : Longman. 939p

COETZEE, J.C. 1977. Inleiding tot die Historiese Opvoedkunde. Johannesburg : Perskor Bockdrukkery. 346p.

CRONJE, G. red. 1967. Aspekte van die Suid-Afrikaanse historiografie. Pretoria : Van Schaik.

CUnNinghaM, P. 1989. Educational History and Educational Change: The Past Decade of English Historiography. History of Education Quarerly, 29(1):77-94, Spring.

DE KLERK, P. 1981. Geskiedenis as kultuurontwikkeling. Pretoria : Butterworth. 181p.

DE VILLIERS, J.H. 1988. Die kwaliteit-gelykhcid-dilemma van die skool. Potchefstroom. (Verhandeling (M.Ed.). PU vir CHO). 256p.

DU TOIT, P.S. 1970. Onderwys in Kaapland. Pretoria : J.L. van Schaik. 174p.

EGGINK, R. 1990. Die wetenskapsteoretiese grondslae van die verkeersveiligheidsopvoeding. (Verhandeling (M.Ed.)- PU vir CHO). 143p.

GRUNDlingH, A. 1990. Politics, Principles and Problems of a Profession: Afrikaner Historians and their Discipline, C. 1920 - C. 1965. Perspectives in Education, 12(1):1-19, Summer.

LOWE, R. \& KANTOR, H. 1989. Considerations on Writing the History of Educational Reform in the 1960's. Educational Theory, 39(1):1-9, Winter.

PIENAAR, J.J. 1974. Temporaliteitspedagogick. Port Elizabeth : Universiteit van Port-Elizabeth. Navorsingspublikasie 66.59 p.

PIENAAR, J.J. 1984. Dic struktuurproblcem in dic pedagogiek. 'n Pedagogiese herbevraging. Port Elizabeth : Universitcit van Port-Elizabeth: Navorsingspublikasie C2. 32p.

POSTMA, W. 1983. Dic motief, struktuur en funksionering van die Transvaalse Onderwysersvereniging. Potchefstroom. (Verhandeling (M.Ed.)- PU vir CHO).

SCHOEMAN, P.G. 1979. Aspekte van die Wysgerige Pedagogiek. Bloemfontcin : SACUM.

SMITH, K. 1988. The Changing Past. Trends in South African Historical Writing. Kaapstad : Southern Book Publishers.

STEYN, J. 1990. Die opvoedingsfilosofiese kontinuitteit tussen die sendingonderwys en onderwys vir swartes na 1953 in dic RSA. Potchefstroom. (Proefskrif (D.Ed.)- PU vir CHO). 208p.

STOKER, H.G. 1961. Beginsels en metodes in dic wetenskap. Potchefstroom : Pro Rege.

STOKER, H.G. 1970. Oorsprong en rigting. Band 2. Kaapstad : Tafelberg-uitgewers. 442p.

STRAUSS, D.F.M. 1978. Inleiding tot dic kosmologie. Blocmfontein : SACUM.

VAN DEN BERG, G.N. 1990. Onderhoud mct outeur. Potchefstroom.

VAN DER SCHIJF, P. 1991. Nuwe geskiedenis, ja... maar people's history? Beeld, Feb. 5.

Koers 57(2) 1992:215-226 
Metodologiese implikasies van vakfilosofiese kwessies rondom die Historiese Opvoedkunde

VAN DER WALT, B.J. 1990. Die Konsekwent Probleem-historiese metode van Filosofiese Historiografie. (In Van der Walt, B.J. Van Athene na Genéve. Potchefstroom : Departement Sentrale Publikasies. p. 1-36.)

VAN DER WALT, J.L. \& DEKKER, E.I. 1983. Fundamentele Opvoedkunde vir onderwysstudente. Silverton : Promedia.

VAN DER WALT, J.L. 1982. Die navorsingsmetode van dic Fundamentele Opvoedkunde. Koers, 47(1):28-44.

VAN DER WALT, J.L. 1988. Navorsing in die filosofiese wetenskappe, met verwysing na die Fundamentele Opvoedkunde. Koers, 53(2):215-232.

VAN DER WALT, J.L. 1990. Geskiedenis van onderwys in Suider-Afrika : 'n uitgebreide bibliografie. (PU vir CHO : RGN-Navorsingsprojek nr. 15/1/3/2/154: Swartonderwysgeskiedenis: 'n persoonsgerigte benadering).

VENTER, 1.S.J. 1976. Die Historiese Opvoedkunde. Oorsprong, grondstrukture, aard en wese. Durban : Butterworths. 258p.

WIERSMA, W. 1986. Research Methods in Education. Boston : Allyn and Bacon. 